\title{
Self-Nudging and the Citizen Choice Architect
}

\author{
Reijula, Samuli ${ }^{1}$ and Hertwig, Ralph ${ }^{2}$ \\ ${ }^{1}$ Theoretical Philosophy / TINT, University of Helsinki, Finland \\ ${ }^{2}$ Center for Adaptive Rationality, Max Planck Institute for Human Development, Berlin, Germany
}

12 April 2020

Forthcoming in Behavioural Public Policy

\begin{abstract}
This article argues that nudges can often be turned into self-nudges: empowering interventions that enable people to design and structure their own decision environments-that is, to act as citizen choice architects. Self-nudging applies insights from behavioral science in a way that is practicable and cost-effective but that sidesteps concerns about paternalism or manipulation. It has the potential to expand the scope of application of behavioral insights from the public to the personal sphere (e.g., homes, offices, families). It is a tool for reducing failures of self-control and enhancing personal autonomy; specifically, self-nudging can mean designing one's proximate choice architecture to alleviate the effects of self-control problems, engaging in education to understand the nature and causes of self-control problems, and employing simple educational nudges to improve goal attainment in various domains. It can even mean self-paternalistic interventions such as winnowing down one's choice set by, for instance, removing options. Policy makers could promote self-nudging by sharing knowledge about nudges and how they work. The ultimate goal of the self-nudging approach is to enable citizen choice architects' efficient self-governance, where reasonable, and the self-determined arbitration of conflicts between their mutually exclusive goals and preferences.
\end{abstract}

Keywords - nudging, choice architecture, boosting, self-control, agency, overconsumption

Homer's Odyssey tells the story of Greek hero Odysseus and his long journey home from the Trojan war. The goddess Circe warns him about the Sirens, beautiful but deadly enchantresses whose singing lures sailors to their deaths on the rocky shores of their island. Reconciling Circe's advice with his own curiosity about the Sirens's song, Odysseus instructs his men to plug their ears with 
beeswax and tie him to the mast of the ship, leaving him there no matter what he says. As they pass the island, Odysseus-bewitched by the Sirens's song-begs his men to untie him. Unable to hear the song, the crew see the Sirens for what they are: dangerous monsters. Acting on Odysseus's orders, they ignore their spellbound captain and row the ship, and Odysseus, to safety.

Informed by Circe's advice and aware of his limited capacity for self-control (or, to use older terminology, willpower), Odysseus resisted temptation by making strategic adjustments to the external world. He manipulated the physical environment by having his men tie him to the mast. In addition, he harnessed the social environment by first inoculating his crew against temptation (having them plug their ears with wax), then recruiting them as guards. The literature on self-control contains numerous examples of strategies that counteract a lack of self-control by modifying physical and social aspects of a person's external world or mental aspects of a person's internal world. Schelling (1984) offered the example of pregnant women, who, anticipating a temporary shift in their preferences for pain relief during labor, ask hospital staff not to have nitrous oxide available in the delivery room. Building on Ainslie (1992) and Ainslie (2001) and Rachlin (2000), Bénabou and Tirole (2004) examined self-control strategies that rely on manipulating the mental environment; they found that good habits and personal rules in organizing one's mental space can help people avoid impulsive behavior.

Many modern temptations are no less insidious than those faced by Odysseus. Environments created by market economies that rely on consumption-based growth often exploit people's biological, psychological, social, and economic vulnerabilities, making it ever easier for people to overconsume (e.g., Swinburn et al. 2011; Roberto et al. 2015; Wu 2017). Take, for instance, the ubiquity of high-caloric, low-cost processed foods and sweetened sodas (Nestle 2013; Nestle 2015). Highly engineered, mass-produced foods and drinks have unleashed novel surges of pleasure-and addiction (Cross and Proctor 2014). Most of the world's population now lives in countries in which overweight 
and obesity kill more people than underweight does (Swinburn, Egger, and Raza 1999). In 2016, 39\% of adults worldwide were overweight and 13\% were obese (WHO 2018), and in 2012, problematic dietary habits were estimated to be associated with around $45 \%$ of cardiometabolic deaths in the US (Micha et al. 2017). The manipulative information environment is another pervasive modern temptation. The information ecology-defined by the internet, smartphones, social media, e-mail, and other online technologies-has created a "check-in" impulse, a "mental itch constantly in need of being scratched" ( $\mathrm{Wu} 2017$, p.186). Like junk food, a low-quality information product offering affirmation, sensationalism, and instant gratification tends to be cheaper and more readily available than high-quality information (Johnson 2015).

People with more self-control-i.e., the "effortful regulation of the self by the self" (Duckworth 2011, p. 2639)-seem better able to achieve their long-term goals, as measured in terms of health, wealth, and other dimensions of human flourishing. According to Moffitt et al. (2011), the capacity for self-control in the first decade of life predicts adult outcomes including income, savings, occupational prestige, and physical and mental health. Against this background, how best can society, individuals, and policy makers respond to the incessant challenges to self-control that characterize the modern world? Policy makers' traditional tools include economic incentives and disincentives such as taxation (e.g., taxing sugary drinks), subsidies (e.g., promoting healthy food consumption; see Thow, Downs, and Jan 2014) and regulations (e.g., limiting access to sugary drinks in schools). Our focus here is not on these traditional tools for steering citizens' behavior but on self-deployed control strategies (see Duckworth, Milkman, and Laibson 2018). Rigid strategies in the spirit of having oneself tied to the mast are impractical for regulating the intake of food, drinks, drugs, and information. For instance, most people are reliant on digital technology in their working lives, meaning that a radical digital detox (as suggested by commentators such as Otto 2016) is out of the question. Legal means of self-regulation are also limited; in many countries, the law does not allow 
individuals to enter into binding agreements with their future selves (e.g., banning themselves from casinos). And research into the effectiveness of voluntary strategies for self-control-from saving loose change to joining Weight Watchers-shows mixed results and relatively low adherence rates (Dansinger et al.2005).

In this article we take another approach, arguing that insights from behavioral science often associated with nudging (see Thaler and Sunstein 2008) offer a rich repertoire of tools for selfdeployed strategies of self-control. We begin by outlining our notion of self-nudging. We then distinguish categories of nudges and summarize the ethical and practical problems of nudging that others have identified. Subsequently, we describe self-nudging as a way of translating behavioral science insights into policy, showing how it can contribute to the discussion on bounded rationality and failures of self-control. Finally, we relate this new approach to the boosting program (Hertwig and Grüne-Yanoff 2017), discussing practical issues associated with the delivery and implementation of self-nudging interventions.

\section{From nudging to self-nudging}

For me, the cues are aural (the ping, the French horn) and visual (pop-ups on the screen). I already knew that putting the phone on silent wasn't enough to break the habit, but ... out of sight could be out of mind. In the mornings, preparing breakfast, I found that it helped to leave the phone in another room. In the car, it went in the glove compartment. When walking around, I'd put it in a zippered pocket.

— Jerome Groopman (2019)

Nudges are nonregulatory and nonmonetary interventions that steer individuals' behaviors toward their ultimate goals (e.g., being healthier, wealthier, and happier) without eliminating any options 
or significantly changing the economic incentives 1 Consider Thaler and Sunstein's (2008) school cafeteria example: Acting as a choice architect, the fictional director of food services for a large city's schools attempts to guide students towards making healthy food choices (without changing the options available) by manipulating psychologically important but economically insignificant aspects of the choice architecture. She rearranges the order of items so that healthy options are positioned early in the line and unhealthy desserts and French fries are moved away from eye-level shelves (for systematic reviews of positional influences and nudge effects on food choice, see Broers et al. 2017, Bucher et al. 2016). As in this example, nudges target aspects of the choice architecture toward which a fully rational homo economicus would be indifferent (e.g., order, defaults, framing), but which matter a great deal to real-world decision makers. Nudges have been applied in domains as diverse as savings, highway safety, consumer protection, energy use, climate change, obesity, education, poverty, and health (Sunstein 2016).

Importantly, the individual being nudged need not be aware of the nudge, let alone of the psychological mechanisms harnessed by the choice architect. In fact, some interventions may be more effective if people know nothing of the intervention or how it works (Holden, Zlatevska, and Dubelaar 2016; but see Loewenstein et al. 2015). Take the effect of changes in food placement on food choice. Food placement is a prominent nudging strategy that follows the rationale that people are less likely to eat food that is harder to reach; simply moving it further away will reduce its consumption (Bucher et al.2016). Altering placement is the nudging intervention with the largest effect on fruit and/or vegetable choice (with $d=.39$ ) featured in Broers et al.'s (2017) meta-analysis. We consulted all 12 articles (14 studies) that were included in their meta-analysis (their table 1). In no single study were participants informed about the specific changes that experimenters made to the choice architecture, nor were they told about the psychological mechanism underlying this strategy.

\footnotetext{
${ }^{1}$ For a careful analysis of the concept(s) of nudge, see Mongin and Cozic (2018)).
} 
Consider another example: "by changing the size of dishware, portion sizes may be reduced leading to unconscious changes in actual food intake" (Bucher et al. 2016, p. 2253). Those being nudged are not necessarily aware of it, and they are even less aware of the psychological mechanisms at work (see also Bovens 2008). That said, there are also cases in which the principles underlying a nudging intervention are made public. For example, the guidelines for behavioral policy interventions issued by the Obama administration required that the principles of the intervention should always be publicized. Importantly, however, even if the explanation is made public, it is unlikely that everyone affected will make the effort to inform themselves.

It is common for an information asymmetry to exist between policy makers and the people being nudged, with policy makers having more and better information. Targeting this asymmetry opens up a new class of policy interventions. We propose that knowledge about nudges and how they work can be actively shared with a target audience, thereby enabling people to address what they perceive as failures of self-control. Let us return to Odysseus and the Sirens. The advice Circe gave Odysseus turned him from a naïve, unsuspecting subject into a psychologically sophisticated agent: he became aware of his vulnerability to enchantment. Perhaps even more importantly, Circe shared a behavioral tool that enabled him to cope with anticipated failures of self-control and to pursue both his short-term and long-term goals: to hear the Sirens' song and to get home safely.

Following this logic, we propose that-if properly informed and instructed-people can enlist nudges for purposes of self-regulation. We refer to this concept as self-nudging $\underbrace{2}$ Self-nudges require awareness of a link between one's behavior and the architecture of the environment, as well as knowledge of a procedural competence that can help to break (or modify) that link. By facilitating the use of self-nudges, public officials and policy makers could enable citizens to become choice

\footnotetext{
${ }^{2}$ The concept of self-nudging has been used by, for instance, Torma, Aschemann-Witzel, and Thøgersen (2018) and Service and Gallagher (2017), and is sometimes mentioned in passing (e.g., Bovens 2008, Footnote 5; Halpern 2016, chapter entitled "Well-being: Nudging ourselves, and each other, to happier lives"). To the best of our knowledge, however, there has not yet been a systematic proposal to harness self-nudging for policy purposes.
} 
architects in their own right, designing their proximate choice architectures in ways that nudge them in desirable directions. From the perspective of public choice architects, facilitating a self-nudge intervention means, first, identifying a choice environment involving a behavioral problem-typically a failure of self-control-that could be avoided or mitigated by redesigning aspects of the environment, and, second, designing and communicating an effective strategy that enables individuals to make the necessary changes in the environment. Specifically, citizens must be informed about the likely causes and determinants of the behavioral problem in question, and how and why the self-nudge could help to address it. This approach is not as out-of-the-ordinary as it may sound. As Schelling (1978) observed, "many of us have little tricks we play on ourselves to make us do the things we ought to do or to keep us from the things we ought to foreswear" (p. 290). For instance, many of us balance letters to be mailed on the front door handle, or keep our daily medication next to our toothbrush. Others learn to avoid temptation by keeping only small amounts of alcohol in the house (Wertenbroch 1998), or deliberately imposing a "waiting period" on themselves by leaving their credit card at home when contemplating a major purchase. Still others use "mental accounting" to save for future goals (Thaler 1999; Drexler, Fischer, and Schoar 2014), transferring part of their salary to a separate bank account earmarked for a specific purpose. All such changes in our proximate choice architecture can also be seen as self-nudges.

What these examples of self-control strategies have in common is that a purely economically rational agent would see no sense in any of them. Yet the simple modifications of the proximate choice environment can help real-life decision makers to control their immediate impulses. Conceptualizing nudges not just as policy tools reserved for behavioral scientists and public policy experts, but as self-nudging tools to which the public can be initiated has a number of benefits. First, the growing number of nudging interventions informed by behavioral science could also be harnessed as self-nudges. Second, nudging interventions could expand the scope of application to the private 
domain, which tends to remain beyond the reach of public choice architects. Third, self-nudging can avoid some of the ethical and practical problems of nudging, as we describe shortly. Let us next consider a classification of nudges that can also inform categories of self-nudges.

\section{Categories of nudges}

Although many nudging interventions work by exploiting a cognitive bias or decisional inadequacy to push a decision maker toward a desirable choice, not all are "non-educative" nudges in this strong sense (Sunstein 2016). Others, such as the provision of information, reminders, or disclosures, can be regarded as "educative nudges." In principle, both educative and noneducative nudges can be turned into self-nudges. However, noneducative nudges are likely to require more sharing of knowledge about the underlying mechanism, as this knowledge is not necessarily part of people's lay theories of behavior or folk psychology.

Different nudges target different aspects of the choice architecture. Focusing on categories of nudges that could, at least in principle, be transformed into self-nudges, we consider five categories and functions (based on Sunstein 2016, and Madrian 2014).

1. Encouraging planning: reminders and prompts. Lack of planning may lead to bad choices, especially when there are competing demands on people's attention. Prompting people to plan in advance and reminding them (e.g., by text message) to follow through has been shown to improve goal attainment in various domains (e.g., voting and vaccination; Milkman et al. 2011; Nickerson and Rogers 2010).

2. Framing and priming. Different ways of framing a situation may lead to contrasting choice behaviors. For instance, one and the same food product could be labelled as $90 \%$ fat-free or as containing $10 \%$ fat, and these logically equivalent framings could induce substantially different 
choices. Similarly, the same set of options in a social situation may lead to different choices depending on whether the situation comes across as a collaborative effort or as a competition among participants (Liberman, Samuels, and Ross 2004).

3. Manipulating accessibility: order and arrangement. The order and perceptual salience of options in choice situations also matter (e.g., Bucher et al. 2016). What people see first when they enter a cafeteria or open a webpage influences their choices. Similarly, reducing inconvenience in the process of, for instance, applying for financial aid for college can increase the chance that students apply for aid and decrease the chance that applicants give up (Madrian 2014)).

4. Eliciting social comparisons and exerting social pressure. People often figure out what appropriate behavior in a situation is by considering what others do (Cialdini and Goldstein 2004). Telling people that "most people pay their taxes on time" or having them compare their energy use with that of their neighbors may promote the desired behavior (Halpern 2016).

5. Providing defaults. Nudge interventions may also target the choice process itself-for example, by setting default options that will hold if the chooser does nothing. It has been demonstrated that switching from an opt-in to an opt-out architecture increases desirable target behaviors (vaccination rates and green-energy use; Madrian 2014; for a meta-analysis of default effects, see Jachimowicz et al.2019).

With these categories in mind, we turn to various ethical and practical problems of nudging.

\section{Ethical and practical problems of nudging}

One key argument in favor of self-nudging is that it addresses various concerns that have been raised about the ethics of nudging (e.g., Glaeser 2006, Rebonato 2012; White 2013, but see also Sunstein 2015)-or at least substantially reduces their force. Here we outline five major criticisms. 
1. Autonomy. Some nudges "typically work better in the dark" (Bovens 2008, p. 209). There are two issues at play here. One is that the fact that a person is being nudged is not being disclosed to them, can be seen to undermine their autonomy (see also House of Lords 2011). The second issue is that people are often unaware of the mechanisms behind the nudge that changes their behavior. To the extent that a nudge exploits cognitive limitations or biases, it shapes behavior in ways that are not necessarily transparent to the chooser. Although nudges aim not to be paternalistic in the sense of putting someone else's normative judgments in the place of the agent's own, some of them nevertheless change behavior by means other than rational persuasion (Hausman and Welch 2010). According to several influential accounts, "the exercise of human agency consists in judgment and behavior ordered by self-conscious reflection about what to think and do" (Doris 2015, p. x). From this perspective, bypassing a decision maker's reflective or deliberative processes threatens their personal autonomy. The crux of the argument becomes clearer if we compare nudge interventions with traditional policy interventions, such as fiscal and regulatory measures (e.g., taxes on cigarettes or laws stipulating that motorcyclists must wear helmets). Such interventions are highly visible, and this visibility safeguards against arbitrary and unreasonable government interference: citizens are able to scrutinize the interventions and hold governments accountable. In this sense, traditional policy interventions treat people as autonomous individuals. Nudges, in contrast, can bypass the processes of deliberative thinking (recall positional effects on food choice) and may thus undermine decision makers' autonomy.

2. Reversibility. Concerns about autonomy are amplified by related worries about reversibility. One defining condition of a nudge is that its effects must be easy for the targeted individual to reverse. Rebonato (2012, see also Mills 2018) argued that nominal reversibility-that is, reversibility in principle-is not the same as reversibility in practice. He suggested that there may even be a trade-off between a nudge's effectiveness and its reversibility. For example, if a nudge works on 
everyone, the fact that only a small fraction of decision makers reject the nudge (e.g., 99.97\% of Hungarians were, by default, presumed to be organ donors because they had not registered otherwise; Johnson and Goldstein 2003) suggests that it may be nominally but not actually reversible. Although many nudges are both visible and public (e.g., graphic health warnings; automatic enrolment in savings plans), others may fly under the radar of the chooser (e.g., unconscious changes in food intake due to positional or order effects), making opting out difficult. Hence, in terms of autonomy and freedom of choice, a nudge may, somewhat paradoxically, be ethically more problematic than a transparently coercive paternalistic intervention: the latter can be more readily detected, deliberated on, and contested.

3. Public versus private domain, and unintended side effects. Nudges are by design local solutions restricted to particular choice settings. Consequently, policy makers are typically only able to influence public choice contexts by nudging - although it is conceivable (and often desirable) that nudging that affects behavior repeatedly (e.g., healthy food choices) generalizes to decisions that are not made in public (Hertwig 2017). Yet many of the behaviors associated with self-control problems lie outside the public sphere, making them difficult for public choice architects to reach. Safe from the eyes of friends and colleagues and from social control and regulatory measures, people may be prone to making late-night visits to the fridge or indulging in a secret chocolate habit. Last but not least, the public nature of nudging interventions may have unintended side effects analogous to moral licensing (Khan and Dhar 2006): the beneficial behavior brought about by a nudge might be canceled out by undesirable behavior elsewhere (Grüne-Yanoff 2016; Hertwig 2017). For example, being nudged to eat healthily in the school cafeteria might lead to indulgence at home.

4. Preference identification. A necessary condition for a nudge to be successful (not just harmless) is that the policy maker knows what makes choosers better off, by their own standards. This raises two problems, one epistemic-methodological and the other conceptual (see Grüne-Yanoff 
and Hertwig 2016). First, how can the policy maker obtain reliable information about the chooser's true preferences? The standard revealed preference interpretation favored by many economists, according to which preferences must be inferred from observed behavior, does not seem like a promising option. The revealed preference approach is assumed to be less biased by cheap talk, strategic considerations, and unreliable introspective abilities. Yet given that observable behavior seems to be driven by a mix of impulsive desires and more reflective judgments, it is not clear how the "real" or true preferences should be inferred from observed behavior (Infante, Lecouteux, and Sugden 2016). In straightforward cases, informal intuitive assessments by policy makers may well be sufficiently accurate. In more complicated contexts, however, it is not safe to assume that experts truly know what is good for choosers, "as judged by themselves" (Thaler and Sunstein 2008, p. 5). Furthermore, in some contexts, choosers explicitly do not want experts to make decisions for them (e.g., medical or end-of-life decisions; Frey, Herzog, and Hertwig 2018). The problem is even more difficult when the targeted population of choosers has heterogeneous preferences (Grüne-Yanoff and Hertwig 2016): one-size-fits-all nudges typically assume that everybody wants the same thing. But can policy makers really assume that everybody wants to save for retirement, for example? In many cases, the assumption of preference homogeneity is questionable, and thus undermines a nudge's goal of enhancing welfare (see Reijula et al. 2018).

The problem of preference identification is particularly acute when nudges are applied to self-control problems. Consider an example put forward by Ariely and Wertenbroch (2002). You go a restaurant that serves a set dinner. Because you are on a diet, you decide beforehand to skip the dessert. But when it is served, you end up eating it anyway, only to regret it afterwards. Such self-control problems appear to involve preferences that are inconsistent over time, as short-term impulsive desires compete with long-term goals. It is important to distinguish between preferences that conflict across time and those which are consistent but increase future costs to the public (e.g., 
lead to higher healthcare premiums or social welfare spending). For instance, someone may crave sweets of all kinds. He knows the price is weight gain—but considers this a price worth paying. Another person lives according to the maxim that it is not the years in your life that count-it is the life in your years. Being true to herself, she hardly saves. A public choice architect who expects both choosers to face health risks and financial risks years down the road may diagnose failures of self-control. Yet both choosers' behavior is fully rational and consistent with their short- and long-term preferences.

But let us assume for the sake of argument that a choice architect is able to identify a chooser's long-term preferences and discovers they are in conflict with their short-term preferences. Even then, it is not clear why long-term preferences are considered indicative of a person's well-being. This has often simply been assumed. Nudges are frequently portrayed as ways of defending the long-term self against externalities imposed on it by the impulsive short-term self (Whitman and Rizzo 2015). In many cases, strengthening the long-term self may be beneficial to overall well-being, and one may argue that long-term preferences reflect the kind of enduring desires and plans that are central to personal identity, and hence worth defending (Bratman 2007). Nonetheless, equating true preferences with long-term preferences is a nontrivial conceptual move. Indeed, Elster (1979), Cowen (1991), and Ainslie (2001) cite counterexamples: overdiscipline can lead to rigidity and loss of enjoyment, and strengthening self-control does not necessarily enhance well-being (as exemplified by misers and anorexics).

Taken together, the prevailing uncertainty about what makes choosers better off, by their own standards, challenges the idea that nudging interventions will automatically enhance people's welfare. It is difficult to measure welfare or happiness, and invariably associating well-being with long-term prudence is conceptually problematic. Against this background, critics of nudging with politically conservative leanings have argued in favor of noninterventionism and a laissez-faire 
approach —of letting things take their own course. We do not share this view. Rather, we believe that behavioral science insights have great potential for improving public policy. In the following, we consider how the behavioral insights gleaned from the nudging approach could inform another policy approach-self-nudging-that is less subject to the practical and ethical problems we have reviewed.

\section{Self-nudging: categories and examples}

The taxonomy of nudges outlined above provides a blueprint for the categories of self-nudges that could, in principle, be shared with citizen choice architects. Some of those categories of nudges lend themselves readily to being mapped onto categories of self-nudges; others, such as priming, are arguably more difficult to self-deploy. Note that the following examples serve as illustrations rather than evidence-based policy interventions, as they have not been subjected to empirical testing.

1. Self-deployed reminders and prompts. Of the categories of nudges identified, reminders and prompts are probably most likely to be part of a decision maker's intuitive behavioral repertoire. People stick reminders on the door so they cannot leave home without seeing them, write and update to-do lists, and use digital calendars to remind them about friends' birthdays. In principle, people could employ such "notes to self" more widely to remind them of behaviors they would like to pursue in situations where they might be tempted to act otherwise. Take, for example, someone who worries about the environmental impact of her food consumption. Although she is aware that meat and dairy have an outsize environmental impact and that dietary changes can deliver significant environmental benefits (Poore and Nemecek 2018), she finds dietary behavior change very hard. Being a self-nudger, she reminds herself of her goal by sticking an illustration of the greenhouse gas emissions associated with various sources of protein to her refrigerator (Moskin et al. 2019). 
Another illustrative reminder and behavioral prompt can help in daily traffic. A car driver can tape a note to their car door handle as a reminder to use the "Dutch reach" method (opening the door with the other hand in order to look back over one's shoulder for cyclists). In theory, these kinds of reminders and prompts help establish behavioral routines, meaning that they become superfluous in the long run.

2. Self-deployed framing. Different ways of framing the same choice can be used to elicit different behaviors. In Mark Twain's (1969) The Adventures of Tom Sawyer, Tom is punished with a chore: whitewashing a fence. When he is teased about his punishment, he frames the task in such positive terms ('Well, I don't see why I oughtn't to like it. Does a boy get a chance to whitewash a fence every day?"; p. 49) that his friends pay him for the "privilege" of doing the chore themselves. Tom uses framing to steer others' behavior, but in principle, framing can be employed to guide oneself as well. Take the example of reward bundling, which refers to reframing a discrete choice as a choice drawn from a set of extended sequences of rewards. Ainslie et al. (2018, pp. 3-4) introduced reward bundling by means of the following example: Imagine a person deciding between jogging in miserable weather or staying in bed for another hour. One approach to framing this choice is to view it as a decision between different activities and experiences over the hour in question. Another approach is to frame the situation as a choice about the kind of person she wants to be in the future: someone who jogs only in perfect conditions, or someone who will maintain their fitness rain or shine. If she believes that her choice today is the best predictor of how she will choose in the future, she may choose to jog today.

Charitable giving offers another example of how people can frame situations for themselves to render choices easier or harder. Sussman, Sharma, and Alter (2015) found that fundraisers could increase contributions by framing donations as exceptional (i.e., uncommon and infrequent) rather than ordinary (i.e., common and frequent) expenses. Framing appears to affect donors' mental 
budgeting processes and diminish the extent to which they considered the effect of the donation on their budgets. In Sussman et al.'s study, people were nudged to donate more. But someone who wants to steer their charity donations could apply the same logic to themself and frame the contributions as either "exceptional" or "ordinary" expenses, thereby making it easier to increase or decrease the magnitude of their donations, depending on their preferences.

3. Self-deployed changes of accessibility, defaults, and friction. Two major design principles of choice architecture are the positioning of objects (e.g., foods) and defaults and, by extension, their cognitive and visual accessibility (Van Gestel, Kroese, and De Ridder 2018, Jachimowicz et al. 2019). Self-nudgers could harness both the repositioning nudge (Van Gestel, Kroese, and De Ridder 2018) and the default nudge. For example, rearranging the refrigerator and kitchen cupboards may be an effective way of controlling one's cravings for sugar and promoting healthier food choices. People could be encouraged to redesign their "personal cafeteria" along the same lines as the school cafeteria: positioning default foods such as fruit and vegetables at eye level and moving temptations such as chocolate cookies to the back of the cupboard.

Torma et al.'s (2018) study of an organic food box subscription offers another example of an opportunity for self-nudging through planning and reorganizing decision environments. Earlier research indicated that preordering food may lead to healthier food choices (VanEpps, Downs, and Loewenstein 2016). Torma and colleagues studied a scheme in which customers signed up to have organic groceries delivered to their doorstep. The hypothesis was that moving from daily supermarket shopping to a preorder scheme would replace a set of low-involvement decisions with high-involvement decisions, and thus facilitate healthier and more environmentally friendly food choices. Many of the customers interviewed had noticed an intention-behavior gap in their shopping behavior and were dissatisfied with being commercially "nudged" into impulse buys in the supermarket. Most believed that the self-nudge of the box scheme helped them to align their 
behavior with their pro-environmental intentions, and to adopt a healthier and more sustainable diet. The box scheme implements several tools from the nudger's toolkit: it manipulates defaults and reorganizes (and gently restricts ${ }^{3}$ ) the available options, making some more accessible than others.

It is hard to think of a modern environment with an architecture more skillfully designed to capture and command control over human behaviors than the online world. Choice architectures online are constructed with the primary goal of maximizing commercial interests (e.g., Wu, 2016). However, as Kozyreva, Lewandowsky, and Hertwig (2019) noted, the very properties of online environments that make it possible to manipulate users' behavior can also be harnessed by individuals to foster their own self-control and motivation. Online environments permit-although rarely encourage-a relatively high level of control over one's choice architecture: users can strategically set their own defaults (e.g., by changing their web browser default home page from a social media site to a high-quality news site to tame the check-in impulse; Marulanda-Carter and Jackson 2012; Wu 2017), adjust or turn off notifications, use grayscale to decrease the salience of eye-catching visual notifications, and install ad blockers. Following the lead of the temptation-resisting children in Mischel's (2015) marshmallow test, self-nudgers can also remove their digital device from sight (see also Groopman 2019, aforementioned attempts at self-nudging). To the extent that these simple modifications to the choice architecture affect frequent behaviors, they can make a meaningful difference. They provide ways of habitually avoiding self-control dilemmas and thus provide people with a means for what Gillebaart and Ridder (2015) refer to as effortless self-control.

A close relative of the category of accessibility manipulations are manipulations that vary the convenience of an option. Consider the jar of chocolate spread that always seems to be empty. One self-nudging intervention is to make enjoying the spread slightly less convenient by putting it in the

\footnotetext{
${ }^{3}$ Self-nudgers can also apply self-paternalistic interventions (Kuklin 1991). This category does not feature in the above nudge taxonomy because nudging by definition excludes hard paternalistic interventions such as removing or forbidding choice options. Self-nudgers, in contrast, can put hard constraints on their own behaviors without curbing the liberty of another person.
} 
fridge: the wait between taking the jar out of the fridge and being able to spread the contents gives the consumer a brief "cooling-off" period. Introducing just a little self-deployed inconvenience, or friction, may often be enough to reduce the behaviors people seek to control (e.g., consuming digital media, eating tasty but unhealthy food, making unwise purchases). By the same token, spotting frictions and removing them may help render desired behaviors more likely.

4. Self-deployed social comparison and social pressure. Another design principle that the self-nudger could adopt is to use commitment devices (Schelling, 1978) that enlist the social world. In their book Think Small, Service and Gallagher (2017) describe ways of using social pressure to precommit oneself. For example, someone who wants to start exercising regularly could make a public commitment to their colleagues. They could even appoint a "commitment referee"-someone who tracks transgressions and enforces a specified penalty in cases of failure (e.g., having to wear the shirt of a rival football team for a day). Moreover, self-nudgers seeking to motivate themselves could strategically select their social comparison group: rather than measuring themselves against a representative peer group, they could construct a mental sample of healthy-living colleagues and friends. Or a self-nudger concerned about his alcohol consumption could find out how his consumption ranks against that of others and use this "rank" framing in a note to himself, thus motivating himself through social comparisons and norms (e.g., Schultz et al. 2007; but the process of perceiving peers' alcohol consumption may be prone to overestimation as demonstrated in Giese, Stok, and Renner 2019).

Let us conclude this initial outline of categories of self-nudges by clearing up a possible misunderstanding. In advocating self-nudging techniques as a means of enhancing self-control, we do not mean to suggest that self-control is the sole cause of various detrimental behaviors. There is little reason to assume that people's capacity for self-control is any worse than it was in the past (in fact, it seems that aspects of self-control such as delay of gratification have increased slightly; 
see Protzko 2020). Rather, we suggest that many commercially constructed environments-such as the modern dietary or information environment-are being deliberately modified to hijack people's desires and impulses (Cross and Proctor 2014; Wu 2017; Dallacker, Mata, and Hertwig 2019):4 The problem is not that people have mysteriously lost their ability for self-control but that past and existing levels of self-control no longer suffice to enable self-governance in these finely tuned choice environments. Boosting consumers' ability to redesign their proximate environment and thus regain at least some of their lost choice autonomy would thus appear desirable.

\section{Self-nudging avoids the ethical and practical problems of nudging}

We do not suggest that self-nudges can solve every self-control problem. Like other policy tools, self-nudging has its limitations: it requires active participation from the people involved, and the details of how to design efficient self-nudging interventions is largely an open research question. We suggest, however, that self-nudging reduces or even eliminates some important drawbacks for which nudging has been criticized.

Autonomy. Because people are educated to nudge themselves, self-nudging does not give rise to concerns about individual autonomy. No outside party modifies the choice environment or behavior in ways that bypass rational deliberation. Critics of nudging point out that making one's own mistakes and learning from them may play an important role in personal growth (Rebonato 2012). As we discuss below in the 'Self-nudging and internal conflict' section, we believe that self-nudges, unlike nudging, enhance self-understanding and provide strategies for negotiating conflicts between impulsive tendencies and long-terms goals. And precisely this learning process can motivate people to self-nudge: only after recognizing a problem and developing the desire to change will people

\footnotetext{
${ }^{4}$ Such environments, constructed by commercial choice architects, often rely on psychological insights that are also used for nudging, but they lack the normative constraint of a nudge: they do not necessarily steer people towards behavior considered as desirable, as judged by themselves.
} 
look for a tool that can help them manage the problem. We should emphasize that self-nudges differ from classic educational interventions in that there is often no need to invest substantial time and effort in acquiring new skills to address undesirable behavior. Self-nudges enable the chooser to smartly manipulate or even experiment with the external environment—consider again the case of the modern online environment-in order to create everyday choice architectures that promote desired choices. In this sense, they enhance rather than undermine autonomy.

Reversibility. Self-nudges escape the reversibility-effectivity dilemma described above. The individual determines how difficult it will be to reverse a self-nudge; self-nudges fall on a continuum ranging from gentle prods and reminders to drastic modifications of the decision environment to be experienced by the future self. Even self-nudges that are difficult to reverse do not involve the power asymmetry characteristic of nudges in which an assumedly naïve chooser faces a knowledgeable policy maker.

Public versus private domain and unintended side-effects. As mentioned earlier, nudges implemented by public choice architects rarely reach—or should reach—people in the privacy of their homes. Self-nudging extends this scope, bringing previously inaccessible personal choice contexts into the realm of benevolent design. Self-nudging also permits a focus on repeated rather than one-off behaviors, which are often the target of nudging interventions (e.g., enrolling in a pension plan). Finally, self-nudging can also, at least in principle, enable people to reverse course when they realize that their self-deployed nudge has unintended side effects. This is not a trivial advantage given that relatively little is known about the long-term effects of many nudging interventions (Frey and Rogers 2014).

Preference identification. It is less obvious how self-nudging could help to tackle the problem of preference identification. Although most of the nudging literature assumes that policy should promote long-term preferences over impulsive desires, it is rare for arguments supporting this 
principle to be explicitly formulated. The principle ultimately seems to hinge on the notions of personal identity and happiness employed (see Hausman 2011; Fumagalli 2016). It may be that informed preferences should not always reflect the need for self-control, but a healthy balance between self-control and self-liberation (Cowen 1991).

How (and when) does a person know what they ultimately want or need? Behavioral science research suggests some methods (e.g., mental contrasting) for clarifying one's goals (Oettingen and Gollwitzer 2004). Admittedly, no self-nudge can be perfectly neutral with respect to the internal process of bargaining between conflicting desires: impulses, temptations, and procrastination versus persistence, abstinence, and action, for example. It is conceivable that becoming an avid self-nudger and manager of one's life might promote a rigid, legalistic, and overly disciplined approach; lapses of willpower due to self-deception, exposure to temptation, or opportunities for moral licensing might be reduced, but at the cost of spontaneity and richness of experience. Some recent suggestions regarding the use of nudges for self-help purposes reinforce such concerns. A micromanaged life driven by repeated milestones and reward schedules will surely lead to loss of spontaneity (e.g., Service and Gallagher 2017, pp. 196-197). Likewise, misers and people struggling with compulsive behavioral patterns constitute prime examples of the results of excessive self-control.

That said, failures of self-control are undoubtedly a more serious cause of human suffering than over-discipline. As Schelling (1985) wrote more than 30 years ago: "I offer the personal judgment that, by and large, people are more in need of greater efficacy in devising rules for their own behavior than in danger of shortsighted self-binding activity" (p. 360). We agree: contemporary phenomena such as obesity, the opioid epidemic, and smartphone addiction are examples of how chemicals, technologies, and manipulative choice environments threaten individual autonomy on a broad scale, with significant individual and social consequences. Commercially constructed choice environments have immense potential to manipulate and steer behavior. It seems 
reasonable to promote self-nudging for self-control purposes to enable people to navigate these environments-especially as it is ultimately up to the individuals themselves how they use these tools. Self-nudging can be seen as a menu of solution ideas that can be consulted whenever people perceive an internal conflict that stops them reaching their goals.

\section{Self-nudging and internal conflict}

Research on boundedly rational agency suggests that the preference identification problem itself may result from a contestable view of human agency and rationality. As we have noted, a common way of modeling self-conflict is to view it as a conflict between two sets of preferences: one describing short-term objectives; the other, long-term objectives. Research on intertemporal choice (Ericson and Laibson 2019) has shown that humans and animals naturally engage in hyperbolic time discounting, which can lead to seemingly irrational preference reversals when they opt for smaller-sooner rewards over larger-later ones. Perhaps, then, the dynamically consistent exponential discounting characteristic of homo economicus should be regarded not as the natural baseline of real-world humans and animals, but as a triumph of self-control. It may be that adult humans (at least sometimes) appear to act in accordance with normative theories of rationality because they are operating in environments in which various cultural, social, and individual self-control resources are available (Ainslie 2001).

This suggests a novel way of thinking about preferences, identity, and the self: "Preferences that are temporary aren't aberrations anymore, but the starting place for a strategic understanding of functions that used to be thought of as organs: the ego, the will, or even the self" (Ainslie 2001, p. 198). In other words, no set of preferences, or short- or long-term desires, need be seen as fundamental. Instead, Ainslie describes the various desires inhabiting human bodies and minds as 
being constantly engaged in limited warfare: the behaviors they recommend are conflicting, but only in part. They tap into the same material resources (the body) and hence recognize the need to engage in mutually beneficial bargaining. Just as bargaining processes may lead to remarkably stable political institutions, they may also produce stable behavioral patterns. The internal rules (such as "never drink beer before 6 p.m.") that emerge from such processes tend to be followed almost ritualistically, and breaking them may feel like violating a social or even moral norm.

This viewpoint provides a novel perspective on nudging interventions: sensitivity to framing and choice architecture does not necessarily reflect irrational aberrations from baseline rational agency. Instead, rational agency is sometimes approximated thanks to good habits, rules, and scaffolding institutions. Information provided in the form of self-nudges could be seen as the contribution of psychological research to that scaffolding. Thus viewed, self-nudging need not be regarded merely a means of impulse control or behavioral self-management. On the contrary, people who see the self as a population of competing desires within a single mind are able to embrace self-conflict and adopt the role of a citizen behavioral scientist experimenting with self-nudges and properties of the environment to determine how they influence behavior. At the risk of sounding lofty, we propose that self-nudges could serve as tools for promoting self-knowledge and internal negotiation between the various needs and desires inhabiting people's minds and bodies. The self-nudging perspective emphasizes the material and practical aspects of this negotiation process: the way people design their choice environments shapes the kinds of affordances and temptations they face in everyday life.

\section{Self-nudges are boosts}

According to proponents of the nudge approach, real-world decision makers are fallible, inconsistent, ill-informed, unrealistically optimistic, and myopic; they suffer from inertia and self-control problems 
(Thaler and Sunstein 2008; see also Halpern 2016). This portrayal of people's decision-making competences has its roots in the heuristics-and-biases program (e.g., Kahneman et al. 1982; Kahneman 2003; Kahneman 2011. The cumulative weight of these cognitive and motivational deficiencies has "raised serious questions about the rationality of many judgments and decisions that people make" (Thaler and Sunstein 2008, p. 7) and both necessitates and enables a new approach to public policy. The innovative core of the nudge approach lies in the insight that policy makers can harness individuals' cognitive and motivational deficiencies and, in combination with a tailored choice architecture, steer people toward behaviors that are consistent with their well-being.

As Hertwig and Grüne-Yanoff (2017; see also Grüne-Yanoff and Hertwig 2016) recently pointed out, however, the portrayal of the human decision maker as systematically imperfect is not the only legitimate one. Behavioral science evidence also supports a distinct kind of intervention, namely "boosts," which Hertwig and Grüne-Yanoff have defined as interventions that target competences rather than immediate behavior: they may enlist human cognition (e.g., decision strategies, procedural routines, motivational competences), the environment (e.g., information representation or the physical environment), or both. The goal is to preserve personal agency and enable individuals to exercise that agency. Consequently, if people endorse the objectives of a boost-say, risk literacy, financial planning, or healthy food choices-they may choose to adopt it; if not, they may decline to engage with it. The objective must thus be transparent to the boosted individuals. They can then harness the new or "boosted" competence to make choices for themselves (e.g., whether to undergo a medical test, consume a particular food, or choose a certain type of investment; see, e.g., Kaufmann, Weber, and Haisley 2013; Dallacker, Mata, and Hertwig 2019; Dallacker, Hertwig, and Mata 2019; Franklin, Folke, and Ruggeri 2019).

Self-nudging is a valuable addition to the booster's toolkit, especially when the goal is to enhance self-control. For example, some biases in human cognition may be so robust that changing them 
by means of boosting would be short-lived, or require too much time or effort. A self-nudge can enable people to steer clear of these biases by manipulating the proximate choice architecture. To do so-and this is where self-nudging and other boosts part ways with traditional nudging-they need to be let in on the secret of why a particular change in the choice architecture achieves a goal, and how it can be implemented. Self-nudges, like all boosts, require a sufficient level of motivation and cognitive capacity on the chooser's part. If their cognitive resources are compromised or their motivation is low, they are unlikely to engage in self-nudging. Having said that, one advantage of self-nudges is that, to the extent that they operate through the environment (e.g., defaults), they may work efficiently even when-and precisely because-motivation and cognitive capacities are limited.5

\section{Returning control}

The idea of self-nudging has relatives and predecessors. One is Schelling's (1978; 1984; 1985) notion of rules and self-commitment devices. Schelling (1985) considered how best to design the rules that people impose on themselves in order to prevent themselves from, for instance, eating too much or driving after drinking. Schelling's concern was with situations in which preferences may shift dramatically: "the coldblooded determination of rules for the hotblooded encounter" (p. 365):

A good rule, if you must sit before a bowl of glistening salted peanuts during an hour's conversation, peanuts being what you are trying to eat as few of as possible, is not to eat the first peanut. Even if your diet allows a few peanuts, it may be easier to draw the line at zero than to stop at your quota after you have whipped your appetite into a frenzy with the first few peanuts. Knowing that the taste of peanuts excites the appetite further

\footnotetext{
${ }^{5}$ One reviewer asked us whether there are also self-boosts. To some extent, all boosts are self-boosts, at least in the long run. Like self-nudges, boosts (e.g., statistical reasoning boost, anti-mathematics anxiety boost; see Hertwig 2017, Hertwig and Grüne-Yanoff 2017) are initially communicated by a policy maker to the target audience; subsequently, however, boosts must be self-deployed. In this sense, boosts are self-boosts.
} 
can help you design a rule-designing the rule can occur when there are no peanuts present and you are not even hungry-that is more readily enforced than a rule to stop after some number of peanuts. (p. 365)

Self-nudges can, of course, also be presented in the form of rules (see Box 1); the difference is that they emphasize the external choice architecture and should, ideally, be informed by empirical evidence obtained in research on the effectiveness of specific nudges.

The notion of letting choice architecture do some of the work that is otherwise delegated to self-control and cognitive oversight was also highlighted by Wansink (e.g., Wansink, Just, and Payne 2009). Although Wansink's empirical work has been subjected to sharp criticism and review, leading to numerous retractions and corrections, his broader idea that empowering people to personally control their food choice architecture (e.g., by not eating with the TV on; Dallacker, Hertwig, and Mata 2018; or storing tempting foods in less convenient locations) has the benefit, like self-nudging, of not requiring people to have the discipline to diet or to relinquish self-governance.

Self-nudging can also be related to the research on self-regulating health-related behaviors (e.g., Mann, De Ridder, and Fujita 2013) in the sense that self-nudges can be understood as strategies that people use to protect their goals from being disrupted by competing goals, temptations, or distractions. The conceptually most interesting part of self-nudging is not, however, conscious, effortful inhibition-"one of the most studied goal striving strategies from a psychological perspective" (Mann, De Ridder, and Fujita 2013, p. 493)-but smartly setting up the choice architecture in accordance with one's goals. Self-nudging, like other self-regulating behavior, emphasizes selfefficacy-that is, boosting people's confidence in being able to exercise control over their behavior and environment to reach their own goals (Bandura 1997).

The concept of stimulus control, an indispensable entry in any textbook on behavioral therapy (e.g., Bootzin and Perlis 2011), is another important predecessor to self-nudging. Stimulus control 
refers to control over the discriminative stimulus (i.e., the antecedent stimulus that has regulates behavior because in the past that behavior was reliably reinforced in the presence of that stimulus). It is key to behavioral therapy across a range of health problems such as sleep disorders, obesity, and substance abuse. Like self-nudging, it focuses on changes in the proximate environment or choice architecture. For instance, stimulus control in the context of weight control could mean:

altering the environment that activates eating and modifying it to help in avoiding overeating. Stimulus control includes proper purchase of food items, excluding energydense processed food from the shopping basket and introduction of more fruits and vegetables. Others include altering the amount of food served on the table or reducing the size of plates and containers, concentrating on eating without being distracted by television or reading material and reducing proximity to food. (Jacob and Isaac 2012, p. 29)

In a narrow sense, stimulus control refers to the voluntary or automatic changes (see also Bugg and Crump 2012) to the environment-for instance, in terms of inserting or removing a stimulus-to change the likelihood of a specific desirable or undesirable behavior. Similar to self-nudging, the goal of any behavioral therapy is that once the therapy or learning phase is terminated, control over the stimulus resides with the person concerned. Stimulus control rests on a different line of psychological theorizing and evidence than does nudging but shares with self-nudging an emphasis on individual agency and control over the choice environment.

To conclude, the idea of self-nudging has various theoretical relatives. One important task for the future will be to work toward integrating these theories and to identify across these lines of research the best evidence-based ways to return self-regulation, autonomy and control over their immediate choice environments to the citizen. 


\section{How to communicate self-nudges}

For citizens to become choice architects in their proximate choice environments, they must be aware of the existence of a behavioral problem, and of how changes in the choice architecture can address it. Self-nudging implies not only learning a "trick"; it also requires some insight into the psychological mechanisms behind it (cf. Marchionni and Reijula 2019). To this end, laypeople need to be let in on behavioral scientists' privileged knowledge of nudging and of how the choice architecture is assumed to function $\sqrt{6}$ This does not imply that they need to become behavioral scientists. Concepts such as cognitive and visual accessibility, cooling-off periods, defaults, and precommitment devices are relatively intuitive and easy to grasp and easy to experiment with (see, e.g., Groopman 2019). Ultimately, to what extent providing citizens with "open access" to behavioral science knowledge can help them achieve their ultimate goals is an empirical question.

The organic food box scheme studied by Torma, Aschemann-Witzel, and Thøgersen (2018) is a concrete example of a self-nudging opportunity set up by a private company. NGOs, government agencies, and consumer protection offices could provide similar services (e.g., voluntary sign-ups for a social media group to monitor energy use) through various communication channels. For example, Lieder et al. (2019) examined how AI-supported apps could help people reach their goals. More traditional means of communication include e-mail and fact boxes. Take, for instance, the UK health services, which send out millions of e-mail reminders per year (Gigerenzer and Muir Gray 2011; Haynes et al. 2013). Reminding people not to miss an appointment is an effective nudge in its own right, but those e-mails could also include a link to a fact box presenting a related self-nudge. Fact

\footnotetext{
${ }^{6}$ In light of severe global health risks such as obesity, it may seem puzzling that most people do remarkably little to construct safer choice architectures for themselves. Why is that? One reason could be that people tend to attribute responsibility for such health risks to the individual, whereas much research suggests that the increase in obesity is primarily due to environmental changes and thus favors obesity-prevention measures that target the environment (Mata and Hertwig 2018). If people perceive the causes of risky behaviors to reside in the individual, they may underestimate the extent to which simple changes in the choice architecture can affect their behavior.
} 
boxes communicate the best available evidence about a specific topic in an easily understandable manner. They were initially developed in the medical domain to contrast the benefits of a medical intervention against potential harms in a clear tabular format that enables people with no medical or statistical background to make competent decisions (Schwartz, Woloshin, and Welch 2009; McDowell et al. 2016). Box 1 presents a fact box on implementation intentions. Prompting people to form an implementation intention (e.g., by writing down a date and time to get a flu shot) has often been classified as a nudge (Thaler and Sunstein 2008; Milkman et al.2011). Here our goal is to enable people to employ it strategically in terms of a self-nudge.

\section{Box 1. Fact box explaining how a self-nudge based on implementation intentions can help people reduce snacking and sugar consumption.}

This fact box explains how to design action plans in order to reduce the likelihood of snacking and consuming added sugar.

What is the problem? Inability to overcome an unhealthy snacking habit (e.g., sweets, potato chips) and to reduce the consumption of added sugar.

What could help to solve the problem? Changing your eating habits is difficult. Even diabetics have difficulties limiting their intake of sugary foods and adopting healthier diets, which can cause serious health problems. Research in psychology has demonstrated that prompting people to develop concrete plans to overcome specific obstacles makes it easier for them to perform a desired behavior $[1,3]$; one area in which this has been shown is healthy eating [4].

Why does developing IF-THEN plans help? It is far easier to make goals than to reach them. Research suggests that formulating concrete IF-THEN plans can help people to attain their goals. A plan taking the form "If situation $\mathrm{x}$ arises, I will do y" is called an implementation 
intention. Implementation intentions are useful because they create a mental association between the desired behavior and a specific future situation. By doing so, they help you not only to get started with your plan, but also to stay on track: Implementation intentions reduce the effort you need to carry out a behavior by making it more automatic, and protect that behavior against competition from other plans, distractions, and temptations. [2] In other words, simple IF-THEN plans specify when, where, and how to reduce the gap between where you are and where you would like to be.

How can I use IF-THEN plans? First, write down a plan of what exactly you intend to eat on a particular weekday (for breakfast, lunch, and dinner). Second, formulate five IF-THEN plans hat specify what you will do if you come up against an obstacle.

For example:

- If a colleague invites me for coffee, I'll buy a banana instead of a piece of cake.

- If I feel the urge to snack while watching TV, I'll get some vegetable sticks with my favorite low-calorie dip.

- If my children have ice cream, I'll pour myself some berries over nonfat Greek yogurt.

\section{How effective are implementation intentions?}

Meta-analytical studies (statistical analyses combining the results of multiple independent studies) have shown that IF-THEN plans can help people achieve their goals (implementation intentions have medium to large effects on goal attainment [1-4]). They help people overcome common problems such as getting started with an intended behavior and staying on track when experiencing difficulties. When combined with imaging how you would like to be in the future, IF-THEN plans can help your behavior in line with intentions, including in sustainable food 
consumption [5], time management [6], getting an influenza shot [7].

\section{References}

1. Gollwitzer, P. M., Sheeran, P. (2006). Implementation intentions and goal achievement: A meta-analysis of effects and processes. Advances in Experimental Social Psychology, $38,69-119$.

2. Gollwitzer, P. M. (2014). Weakness of the will: Is a quick fix possible? Motivation and Emotion, 38(3), 305-322.

3. Adriaanse, M. A., Vinkers, C. D. W., De Ridder, D. T. D., Hox, J. J., De Wit, J. B. F. (2010). Do implementation intentions help to eat a healthy diet? A systematic review and meta-analysis of the empirical evidence. Appetite, 56(1), 183-193.

4. Chen, X., Wang, Y., Liu, L., Cui, J., Gan, M., Shum, D. H. K., Chan, R. C. K. (2015). The effect of implementation intention on prospective memory: A systematic and meta-analytic review. Psychiatry Research, 226(1), 14-22.

5. Loy, L. S., Wieber, F., Gollwitzer, P. M., Oettingen, G. (2016). Supporting sustainable food consumption: Mental contrasting with implementation intentions (MCII) aligns intentions and behavior. Frontiers in Psychology, 7, 607.

6. Oettingen, G., Kappes, H. B., Guttenberg, K. B., Gollwitzer, P. M. (2015). Self-regulation of time management: Mental contrasting with implementation intentions. European Journal of Social Psychology, 45(2), 218-229. Milkman, K. L., Beshears, J., Choi, J. J., Laibson, D., Madrian, B. C. (2011). Using implementation intentions prompts to 
enhance influenza vaccination rates. Proceedings of the National Academy of Sciences, 108(26), 10415-10420.

Fact boxes like the one shown in Box 1 could be designed for a wide range of self-nudges. In the context of healthy eating, these include defaults, ordering effects, and even the architectural properties of the family meal (see Dallacker, Hertwig, and Mata 2018). We propose that a fact box describing a self-nudge should include five main pieces of information: (1) a description of the behavioral problem; (2) a description of a suitable self-nudge; (3) an explanation of the psychological mechanisms underlying the self-nudge, and how it can help to mitigate the problem; (4) an actionable description of how to implement the nudge (if necessary, with links to additional tools and resources, e.g., a hyperlink to an app); (5) if available, a list of the possible benefits and potential side effects (in terms of easily understandable effect sizes). This fifth dimension is ambitious. Research-based interventions should not be oversold but communicated truthfully. Little evidence on the benefits and harms of self-nudges is yet available; currently it would need to be extrapolated from the nudging literature or from the relevant primary literature (as in our example of implementation intentions). Consider, for example, the essential topic of potential side effects of a self-nudge. Having steered oneself to exercise a desired behavior such as not eating that first peanut (Schelling 1985), an individual may feel justified in engaging in behaviors that they would otherwise avoid, such as drinking another glass of wine. The risk of this kind of "moral self-licensing" (e.g., Monin and Miller 2001) may increase when people successfully nudge themselves. Whether it indeed occurs is an empirical question. But if it does, this information would need to be communicated in the fact box. Similarly, while social comparisons have often been found to be useful for goal achievement, they may also compromise performance (Gollwitzer et al. 2009)-a finding that a fact box would need to communicate.

As a valuable starting point, Duckworth, Milkman, and Laibson (2018) have reviewed the 
evidence for various self-deployed (situational and cognitive) self-control strategies. Obviously there is also a need for research into the effectiveness of self-nudging. Such research would permit policy makers to build up a repertoire of self-nudges and communicate their respective strengths and weaknesses to the public (e.g., in fact boxes and apps). This is a vision for the future-but one in which researchers who otherwise disagree about people's decision-making competences (see Hertwig and Grüne-Yanoff 2017) may be able to join forces.

\section{Conclusion}

Commercial choice architects have become proficient in hijacking people's attention and desires (see, e.g., Nestle 2013; Nestle 2015; Cross and Proctor 2014; Wu 2017), making it difficult for consumers to exercise agency and freedom of choice. Even in the best of circumstances, the potential for public choice architects to nudge people toward better choices in their personal and proximate choice environments is limited. Against this background, we suggest that policy makers should consider the possibility of empowering individuals to make strategic changes in their proximate choice architecture. There is no reason why citizens should not be informed about nudges that can be turned into self-nudges and, more generally, about the design principles of choice environments (e.g., defaults, framing, cognitive accessibility). We suggest that self-nudging is an untapped resource that sidesteps various ethical and practical problems associated with nudging and can empower people to make better everyday choices. This does not mean that regulation or nudging should be replaced by self-nudging; indeed, self-nudging can benefit enormously from the ingenuity of the nudging approach and the evidence accumulating on it. But, as the adage goes, give someone a fish, and you feed them for a day. Teach someone to fish, and you feed them for a lifetime. We believe that sharing behavioral insights from psychology and behavioral economics will provide citizens with a 
means for taking back power, giving them more control over the design of their proximate choice environments-in other words, qualifying them as citizen choice architects.

\section{Acknowledgments}

The authors would like to thank Mattea Dallacker, Jutta Mata, Susan Michie, Michiru Nagatsu, Cass Sunstein, Susanne Uusitalo and Claus Vögele for helpful comments on the concept of self-nudging and Susannah Goss for editing the manuscript.

\section{Financial support}

Samuli Reijula's research was funded by the Academy of Finland and the Kone Foundation. 
The citizen choice architect

\section{References}

Ainslie, G. (1992). Picoeconomics: The strategic interaction of successive motivational states within the person. Cambridge University Press.

- (2001). Breakdown of will. Cambridge University Press.

Ainslie, G. et al. (2018). Do people bundle sequences of choices? An experimental investigation. Experimental Economics Center, Andrew Young School of Policy Studies ...

Ariely, D. and K. Wertenbroch (2002). "Procrastination, deadlines, and performance: Self-control by precommitment". In: Psychological science 13.3, pp. 219-224.

Bandura, A. (1997). "Self-efficacy: The exercise of control". In: H. Freeman, New York, NY.

Bénabou, R. and J. Tirole (2004). "Willpower and personal rules". In: Journal of Political Economy 112.4, pp. 848-886.

Bootzin, R. R. and M. L. Perlis (2011). "Stimulus control therapy". In: Behavioral Treatments for Sleep Disorders. Elsevier, pp. 21-30.

Bovens, L. (2008). "The ethics of nudge". In: Preference Change: Approaches from Philosophy, Economics and Psychology. Ed. by M. J. Hansson and T. Grüne-Yanoff. Berlin: Springer, Theory and Decision Library A, pp. 207-20.

Bratman, M. E. (2007). Structures of agency: Essays. Oxford University Press.

Broers, V. J. et al. (2017). "A systematic review and meta-analysis of the effectiveness of nudging to increase fruit and vegetable choice". In: The European Journal of Public Health 27.5, pp. 912-920.

Bucher, T. et al. (2016). "Nudging consumers towards healthier choices: a systematic review of positional influences on food choice". In: British Journal of Nutrition 115.12, pp. 2252-2263.

Bugg, J. M. and M. J. Crump (2012). "In support of a distinction between voluntary and stimulusdriven control: A review of the literature on proportion congruent effects". In: Frontiers in psychology 3, p. 367.

Cialdini, R. B. and N. J. Goldstein (2004). "Social influence: Compliance and conformity". In: Annu. Rev. Psychol. 55, pp. 591-621.

Cowen, T. (1991). "Self-constraint versus self-liberation". In: Ethics 101.2, pp. 360-373.

Cross, G. S. and R. Proctor (2014). Packaged pleasures: How technology and marketing revolutionized desire. University of Chicago Press.

Dallacker, M., R. Hertwig, and J. Mata (2018). "The frequency of family meals and nutritional health in children: a meta-analysis". In: Obesity Reviews 19.5, pp. 638-653.

- (2019). "Quality matters: A meta-analysis on components of healthy family meals." In: Health Psychology 38.12, p. 1137.

Dallacker, M., J. Mata, and R. Hertwig (2019). "Toward simple eating rules for the land of plenty". In: Taming uncertainty. Ed. by Hertwig, Ralph, Pleskac, Timothy, and Pachur, Thorsten. MIT Press, pp. 111-130. 
Dansinger, M. L. et al. (2005). "Comparison of the Atkins, Ornish, Weight Watchers, and Zone diets for weight loss and heart disease risk reduction: a randomized trial”. In: Jama 293.1, pp. 43-53.

Doris, J. M. (2015). Talking to our selves: Reflection, ignorance, and agency. Oxford University Press.

Drexler, A., G. Fischer, and A. Schoar (2014). "Keeping it simple: Financial literacy and rules of thumb”. In: American Economic Journal: Applied Economics 6.2, pp. 1-31.

Duckworth, A. L. (2011). "The significance of self-control". In: Proceedings of the National Academy of Sciences 108.7, pp. 2639-2640.

Duckworth, A. L., K. L. Milkman, and D. Laibson (2018). "Beyond willpower: Strategies for reducing failures of self-control". In: Psychological Science in the Public Interest 19.3, pp. 102-129.

Elster, J. (1979). Ulysses and the sirens: Studies in rationality and irrationality. Cambridge, England: Cambridge University Press.

Ericson, K. M. and D. Laibson (2019). "Intertemporal choice”. In: Handbook of Behavioral Economics: Applications and Foundations 1. Vol. 2. Elsevier, pp. 1-67.

Franklin, M., T. Folke, and K. Ruggeri (2019). "Optimising nudges and boosts for financial decisions under uncertainty". In: Palgrave Communications 5.1, pp. 1-13.

Frey, E. and T. Rogers (2014). "Persistence: How treatment effects persist after interventions stop". In: Policy Insights from the Behavioral and Brain Sciences 1.1, pp. 172-179.

Frey, R., S. M. Herzog, and R. Hertwig (2018). "Deciding on behalf of others: a population survey on procedural preferences for surrogate decision-making”. In: BMJ open 8.7, e022289.

Fumagalli, R. (2016). "Decision sciences and the new case for paternalism: three welfare-related justificatory challenges". In: Social Choice and Welfare 47.2, pp. 459-480.

Giese, H., F. M. Stok, and B. Renner (2019). "Perceiving college peers' alcohol consumption: temporal patterns and individual differences in overestimation". In: Psychology \& health 34.2, pp. 147-161.

Gigerenzer, G. and J. A. Muir Gray (2011). Better doctors, better patients, better decisions. Envisioning healthcare 2020. London: MIT Press.

Gillebaart, M. and D. T. de Ridder (2015). "Effortless self-control: A novel perspective on response conflict strategies in trait self-control". In: Social and Personality Psychology Compass 9.2, pp. 88-99.

Glaeser, E. (2006). "Psychology and Paternalism”. In: U Chi L Rev 73, p. 133.

Gollwitzer, P. M. et al. (2009). "When intentions go public: Does social reality widen the intentionbehavior gap?" In: Psychological science 20.5, pp. 612-618.

Groopman, J. (Oct. 21, 2019). “Can brain science help us break bad habits?” In: The New Yorker. URL: https://www.newyorker.com/magazine/2019/10/28/can-brain-science-help-us-break-bad$\% 20$ habits.

Grüne-Yanoff, T. (2016). "Why behavioural policy needs mechanistic evidence". In: Economics \& Philosophy 32.3, pp. 463-483.

Grüne-Yanoff, T. and R. Hertwig (2016). "Nudge versus boost: How coherent are policy and theory?" In: Minds and Machines 26.1, pp. 149-183. 
Halpern, D. (2016). Inside the nudge unit: How small changes can make a big difference. Random House.

Hausman, D. M. (2011). Preference, value, choice, and welfare. Cambridge University Press.

Hausman, D. M. and B. Welch (2010). "Debate: To nudge or not to nudge*". In: Journal of Political Philosophy 18.1, pp. 123-136. (Visited on 04/24/2020).

Haynes, L. C. et al. (2013). "Collection of delinquent fines: An adaptive randomized trial to assess the effectiveness of alternative text messages". In: Journal of Policy Analysis and Management 32.4, pp. 718-730. (Visited on 04/24/2020).

Hertwig, R. (2017). "When to consider boosting: some rules for policy-makers". In: Behavioural Public Policy 1.2, pp. 143-161.

Hertwig, R. and T. Grüne-Yanoff (2017). "Nudging and boosting: Steering or empowering good decisions". In: Perspectives on Psychological Science 12.6, pp. 973-986.

Holden, S. S., N. Zlatevska, and C. Dubelaar (2016). "Whether smaller plates reduce consumption depends on who's serving and who's looking: a meta-analysis". In: Journal of the Association for Consumer Research 1.1, pp. 134-146.

House of Lords (2011). Behaviour change (second report).

Infante, G., G. Lecouteux, and R. Sugden (2016). "Preference purification and the inner rational agent: a critique of the conventional wisdom of behavioural welfare economics". In: Journal of Economic Methodology 23.1, pp. 1-25.

Jachimowicz, J. M. et al. (2019). "When and why defaults influence decisions: A meta-analysis of default effects". In: Behavioural Public Policy 3.2, pp. 159-186.

Jacob, J. J. and R. Isaac (2012). "Behavioral therapy for management of obesity". In: Indian Journal of Endocrinology and Metabolism 16.1, pp. 28-32. (Visited on 04/24/2020).

Johnson, C. A. (2015). The information diet: A case for conscious comsumption. " O'Reilly Media, Inc."

Johnson, E. and D. Goldstein (2003). "Do defaults save lives?” In: Science 302.5649, pp. 1338-1339.

Kahneman, D. (2003). "A perspective on judgment and choice: mapping bounded rationality." In: American psychologist 58.9, p. 697.

- (2011). Thinking, fast and slow. 1st ed. Farrar, Straus and Giroux. 512 pp.

Kahneman, D. et al. (1982). Judgment under uncertainty: Heuristics and biases. Cambridge university press.

Kaufmann, C., M. Weber, and E. Haisley (2013). "The role of experience sampling and graphical displays on one's investment risk appetite". In: Management science 59.2, pp. 323-340.

Khan, U. and R. Dhar (2006). "Licensing effect in consumer choice". In: Journal of marketing research 43.2 , pp. 259-266.

Kozyreva, A., S. Lewandowsky, and R. Hertwig (2019). "Citizens versus the internet: Confronting digital challenges with cognitive tools". In: (under review).

Kuklin, B. (1991). "Self-paternalism in the marketplace". In: U. Cin. L. Rev. 60, p. 649. 
Liberman, V., S. M. Samuels, and L. Ross (2004). "The name of the game: Predictive power of reputations versus situational labels in determining prisoner's dilemma game moves". In: Personality and social psychology bulletin 30.9, pp. 1175-1185.

Lieder, F. et al. (2019). “Cognitive prostheses for goal achievement”. In: Nature human behaviour 3.10 , pp. 1096-1106.

Loewenstein, G. et al. (2015). "Warning: You are about to be nudged". In: Behavioral Science \& Policy 1.1, pp. 35-42.

Madrian, B. C. (2014). "Applying insights from behavioral economics to policy design". In: Annu. Rev. Econ. 6.1, pp. 663-688.

Mann, T., D. De Ridder, and K. Fujita (2013). "Self-regulation of health behavior: social psychological approaches to goal setting and goal striving." In: Health Psychology 32.5, p. 487.

Marchionni, C. and S. Reijula (2019). "What is mechanistic evidence, and why do we need it for evidence-based policy?” In: Studies in History and Philosophy of Science Part A 73, pp. 54-63.

Marulanda-Carter, L. and T. W. Jackson (2012). "Effects of e-mail addiction and interruptions on employees". In: Journal of Systems and Information Technology.

Mata, J. and R. Hertwig (2018). "Public beliefs about obesity relative to other major health risks: representative cross-sectional surveys in the USA, the UK, and Germany". In: Annals of Behavioral Medicine 52.4, pp. 273-286.

McDowell, M. et al. (2016). "A simple tool for communicating the benefits and harms of health interventions: a guide for creating a fact box". In: MDM Policy \& Practice 1.1.

Micha, R. et al. (2017). "Association between dietary factors and mortality from heart disease, stroke, and type 2 diabetes in the United States". In: Jama 317.9, pp. 912-924.

Milkman, K. L. et al. (2011). "Using implementation intentions prompts to enhance influenza vaccination rates". In: Proceedings of the National Academy of Sciences 108.26, pp. 1041510420.

Mills, C. (2018). “The choice architect's trilemma”. In: Res Publica 24.3, pp. 395-414.

Mischel, W. (2015). The marshmallow test: Why self-control is the engine of success. Little, Brown.

Moffitt, T. E. et al. (2011). "A gradient of childhood self-control predicts health, wealth, and public safety”. In: Proceedings of the national Academy of Sciences 108.7, pp. 2693-2698.

Mongin, P. and M. Cozic (2018). "Rethinking nudge: not one but three concepts". In: Behavioural Public Policy 2.1, pp. 107-124.

Monin, B. and D. T. Miller (2001). "Moral credentials and the expression of prejudice." In: Journal of personality and social psychology 81.1, p. 33.

Moskin, J. et al. (Apr. 30, 2019). "Your questions about food and climate change, answered". In: The New York Times.

Nestle, M. (2013). Food politics: How the food industry influences nutrition and health. Vol. 3. Univ of California Press.

- (2015). Soda politics: Taking on big soda (and winning). Oxford University Press, USA.

Nickerson, D. W. and T. Rogers (2010). "Do you have a voting plan? Implementation intentions, voter turnout, and organic plan making”. In: Psychological Science 21.2, pp. 194-199. 
Oettingen, G. and P. M. Gollwitzer (2004). "Goal setting and goal striving". In: Emotion and motivation. Perspectives on social psychology. Malden: Blackwell Publishing, pp. 165-183.

Otto, D. (2016). Digital Detox: Wie Sie entspannt mit Handy \& Co. leben. Springer.

Poore, J. and T. Nemecek (2018). "Reducing food's environmental impacts through producers and consumers". In: Science 360.6392, pp. 987-992.

Protzko, J. (2020). "Kids these days! Increasing delay of gratification ability over the past 50 years in children". In: Intelligence 80, p. 101451.

Rachlin, H. (2000). The science of self-control. Harvard University Press.

Rebonato, R. (2012). Taking liberties: A critical examination of libertarian paternalism. Palgrave Macmillan.

Reijula, S. et al. (2018). "Nudge, boost or design? Limitations of behavioral policy under social interaction". In: The Journal of Behavioral Economics for Policy 2.1, pp. 99-105.

Roberto, C. A. et al. (2015). "Patchy progress on obesity prevention: emerging examples, entrenched barriers, and new thinking". In: The Lancet 385.9985, pp. 2400-2409.

Schelling, T. C. (1978). "Egonomics, or the art of self-management". In: The American Economic Review 68.2, pp. 290-294.

- (1984). "Self-command in practice, in policy, and in a theory of rational choice". In: The American Economic Review 74.2, pp. 1-11.

— (1985). "Enforcing rules on oneself". In: JL Econ. \& Org. 1, p. 357.

Schultz, P. W. et al. (2007). "The constructive, destructive, and reconstructive power of social norms". In: Psychological science 18.5, pp. 429-434.

Schwartz, L. M., S. Woloshin, and H. G. Welch (2009). "Using a drug facts box to communicate drug benefits and harms: two randomized trials". In: Annals of Internal Medicine 150.8, pp. 516-527.

Service, O. and R. Gallagher (2017). Think small: The surprisingly simple ways to reach big goals. Michael O'Mara Books Limited London.

Sunstein, C. R. (2015). “The ethics of nudging”. In: Yale J. on Reg. 32, p. 413.

- (2016). "The council of psychological advisers". In: Annual Review of Psychology 67, pp. 713737.

Sussman, A. B., E. Sharma, and A. L. Alter (2015). "Framing charitable donations as exceptional expenses increases giving." In: Journal of Experimental Psychology: Applied 21.2, p. 130.

Swinburn, B. A. et al. (2011). "The global obesity pandemic: shaped by global drivers and local environments". In: The Lancet 378.9793, pp. 804-814.

Swinburn, B., G. Egger, and F. Raza (1999). "Dissecting obesogenic environments: the development and application of a framework for identifying and prioritizing environmental interventions for obesity". In: Preventive medicine 29.6, pp. 563-570.

Thaler, R. H. (1999). "Mental accounting matters". In: Journal of Behavioral decision making 12.3, pp. 183-206.

Thaler, R. and C. Sunstein (2008). Nudge: improving decisions about health, wealth, and happiness. New Haven ; London: Yale University Press. 
Thow, A. M., S. Downs, and S. Jan (2014). "A systematic review of the effectiveness of food taxes and subsidies to improve diets: understanding the recent evidence". In: Nutrition reviews 72.9 , pp. 551-565.

Torma, G., J. Aschemann-Witzel, and J. Thøgersen (2018). "I nudge myself: Exploring 'selfnudging'strategies to drive sustainable consumption behaviour". In: International journal of consumer studies 42.1, pp. 141-154.

Twain, M. (1969). The adventures of Tom Sawyer; Tom Sawyer Abroad; Tom Sawyer, detective. Nelson Doubleday.

Van Gestel, L. C., F. M. Kroese, and D. T. D. De Ridder (2018). "Nudging at the checkout counter-A longitudinal study of the effect of a food repositioning nudge on healthy food choice". In: Psychology \& health 33.6, pp. 800-809.

VanEpps, E. M., J. S. Downs, and G. Loewenstein (2016). "Advance ordering for healthier eating? Field experiments on the relationship between the meal order-consumption time delay and meal content". In: Journal of Marketing Research 53.3, pp. 369-380.

Wansink, B., D. R. Just, and C. R. Payne (2009). "Mindless eating and healthy heuristics for the irrational". In: American Economic Review 99.2, pp. 165-69.

Wertenbroch, K. (1998). "Consumption self-control by rationing purchase quantities of virtue and vice”. In: Marketing Science 17.4, pp. 317-337. (Visited on 04/24/2020).

White, M. (2013). The manipulation of choice: Ethics and libertarian paternalism. Springer.

Whitman, D. G. and M. J. Rizzo (2015). "The problematic welfare standards of behavioral paternalism". In: Review of Philosophy and Psychology 6.3, pp. 409-425.

WHO (2018). Obesity and overweight. Fact sheet. URL: http://www.who.int/mediacentre/ $\% 20$ factsheets/fs311/en/

$\mathrm{Wu}, \mathrm{T}$. (2017). The attention merchants: The epic scramble to get inside our heads. Vintage. 